\title{
DEGRADATION OF THE ERYTHROCYTE PHOSPHOLIPIDS AND HAEMOLYSIS OF THE ERYTHROCYTES OF DIF- FERENT ANIMAL SPECIES BY LEPTOSPIRAE
}

\author{
L. B. KASĂROV* \\ Laboratori di Microbiologia, Istituto Superiore di Sanità, and Centro Nazionale Chimico del \\ Farmaco del CNR, Istituto Chimico, Università Cattolica, Roma, Italy \\ Plate I
}

THE production of a haemolytic factor by some parasitic serotypes of leptospirae was reported by Russel $(1954,1956)$, Alexander et al. (1956) and van Riel (1959).

This factor was designated a haemolysin. Pentek-Juhasz (1960) observed that cultures of saprophytic leptospirae contained a factor causing haemolysis of mouse and rat erythrocytes. Kmety et al. (1966) showed that strains belonging to the parasitic serotypes pomona, grippotyphosa and bataviae also haemolysed mouse and rat erythrocytes. Rogols, Fizette and Bohl (1959) pointed out that the nature and activity of the leptospiral haemolysin resemble those of an enzyme. On the basis of the observations that erythrocyte stromata, like lecithin, yield white floccules when mixed with leptospiral haemolysin, as they also do when mixed with the $\alpha$-toxin of Clostridium welchii, and that some lecithinase inhibitors also inhibit the haemolytic activity of the leptospirae, they suggested that the lysis of erythrocytes by leptospiral haemolysin may be due to the action of enzymes on the phospholipids of the red cells.

The present study was undertaken to discover whether phospholipids in the erythrocyte membrane are degraded by leptospiral enzymes and whether such degradation is associated with haemolysis.

\section{MATERIALS AND METHODS}

Organisms. Observations were made both with saprophytic and with parasitic strains of leptospirae taken from the collection of the WHO/FAO Leptospira Reference Laboratory, Istituto Superiore di Sanità, Rome. The saprophytic strains were: serotype patoc strain Patoc 1, serotype são paulo strain São Paulo, serotype doberdo strain Doberdo 1, serotype basovizza strains Basovizza, Dindio (not yet classified) and AM20 (not yet classified). The parasitic strains were: serotype copenhageni strains Wjinberg and Ratto 67, serotype icterohaemorrhagiae strains RGA and Bianchi 1, serotype ndambari strain Ndambari, serotype pomona strains Pomona, Mezzano 1, Simon, To-Cumiana and Monjakov DVB, serotype grippotyphosa strains Moskva V, Mallersdorf, Vitulina and RM2, serotype bataviae strain Pavia 1, serotype djatzi strain HL26, and serotype zanoni strain Zanoni.

Korthof's medium, as modified by Babudieri (1961), in amounts of $30 \mathrm{ml}$ was used for cultivation of the leptospirae. Well-grown whole cultures, incubated for $10-30$ days at $30^{\circ} \mathrm{C}$, and checked for the absence of bacterial contamination, were used in the tests.

Received 4 Feb. 1969; accepted 28 May 1969.

* Research Institute of Epidemiology and Microbiology, Sofia, Bulgaria. Present address: Department of Microbiology, Hahnemann Medical College, Philadelphia, Pennsylvania, USA.

J. MED. MICROBIOL.—VOL. 3 (1970) 
Preparation of erythrocyte suspensions. Human and sheep blood was collected by aseptic venepuncture. Rabbit and rat blood was obtained by heart puncture. Erythrocytes were separated from defibrinated blood and washed three times by suspension in a sterile solution of 0.85 per cent. $\mathrm{NaCl}$ and centrifugation for $10 \mathrm{~min}$. at 3000 r.p.m. (2000g). The packed cells were resuspended in a sufficient volume of the same saline solution to give a 20 per cent. (v/v) suspension. The experiments were made 4-20 hr after collection of the blood. Osmotic haemolysates were prepared by adding three volumes of distilled water to one volume of packed erythrocytes.

Extraction of lipids from the erythrocytes. The lipids were extracted by Bragdon's method for serum lipids as modified by Jover (1963) and adapted to the present purpose. The test mixture of leptospiral culture $(3 \mathrm{ml})$ and erythrocyte suspension $(1 \mathrm{ml} 20$ per cent. suspension) was mixed with $24 \mathrm{ml}$ of a mixture of chloroform, 2 vol., and methanol, 1 vol., and placed in an Erlenmeyer flask with a glass stopper. The flask was shaken for $20 \mathrm{~min}$. and $2 \mathrm{ml}$ distilled water was added. The flask was inverted ten times and the contents were centrifuged at $2000 \mathrm{~g}$ for $15 \mathrm{~min}$. at $4^{\circ} \mathrm{C}$. Three layers were formed: a lower layer of chloroform containing all the lipids, a middle layer of tightly packed proteins and red cells or red cell ghosts, and an upper layer of aqueous alcohol. The chloroform layer was removed and evaporated to dryness in vacuo. To avoid losses of lysophospholipids the lipid extracts were not washed for the removal of non-lipid materials such as amino acids. The dried extract of lipids was dissolved in $0.2 \mathrm{ml}$ chloroform-methanol $4: 1(\mathrm{v} / \mathrm{v})$ and transferred to the thin-layer plates in amounts of $0.04 \mathrm{ml}$.

Thin-layer chromatography. Analysis of the total lipid extract for phospholipids was carried out on glass plates $(20 \times 20 \mathrm{~cm})$ coated with silica gel $\mathrm{G}$ containing 13 per cent. $\mathrm{CaSO}_{4} \cdot \frac{1}{2} \mathrm{H}_{2} \mathrm{O}$ (E. Merck, Darmstadt, Germany) to a thickness of $0.30 \mathrm{~mm}$. Plates were dried in air, activated at $110^{\circ} \mathrm{C}$ for $1 \mathrm{hr}$ and stored in a desiccator until used. The developing system consisted of chloroform-methanol-water, $65: 25: 4(\mathrm{v} / \mathrm{v} / \mathrm{v})$ (Marinetti, 1962). Spots of the amino-nitrogen-containing phospholipids were made visible by the use of the ninhydrin reagent and then the spots of choline-containing phospholipids were developed with the Dragendorf reagent. The spots were identified by comparing their mobility with those of pure phospholipids serving as markers. The lipid extract contained a certain amount of amino acids. In the chromatograms made for the figures (figs. 1-4), the zone of the spots corresponding to the amino acids, which is near the origin, was not treated with the ninhydrin reagent. Pure preparations of lecithin, lysolecithin and sphingomyelin were obtained through the courtesy of Professor L. L. M. van Deenen, of the State University of Utrecht, Netherlands, DL- $\alpha$-phosphatidyl ethanolamine was purchased from Nutritional Biochemicals Corporation, Cleveland, Ohio, USA, and phosphatidyl serine from General Biochemicals, Chagrin Falls, Ohio, USA.

Procedure for testing the effect of leptospirae on the erythrocyte phospholipids. Replicate tubes containing $1 \mathrm{ml}$ of a 20 per cent. suspension of erythrocytes and $3 \mathrm{ml}$ of the leptospira culture rendered isotonic by the addition of $0.1 \mathrm{ml}$ of a 22.5 per cent. $\mathrm{NaCl}$ solution were incubated for $4-96 \mathrm{hr}$ at $37^{\circ} \mathrm{C}$. In the control tests $3 \mathrm{ml}$ isotonic Korthof's medium was added instead of leptospiral culture. Extraction and analyses of the lipids were carried out at intervals during incubation. Before the extraction a further test was made for the absence of bacterial contamination. Because many enzymes having phospholipids as substrates are activated by calcium ions the tests were performed in parallel, with and without the addition of $\mathrm{CaCl}_{2}(20 \mu$.moles to $1 \mathrm{ml}$ of the erythrocyte suspension) to the assay mixture. Korthof's medium as modified by Babudieri does not contain $\mathrm{CaCl}_{2}$, and the sources of calcium ions in the system were some of the ingredients of the medium, mainly the rabbit serum and peptone. It may be assumed, however, that the concentration of calcium ions in the presence of the phosphate ions in the medium was very low, and probably insufficient to activate the leptospiral enzymes.

Test for haemolytic activity of leptospirae. The mixture of leptospiral culture and erythrocyte suspension used in the assay procedure for testing the effect of leptospirae on the erythrocyte phospholipids served simultaneously as a haemolytic system. The system was observed for haemolysis at intervals of $4 \mathrm{hr}$. 


\section{RESULTS}

\section{Changes in the phospholipid content of intact erythrocytes}

Chromatographic analysis of phospholipids extracted from washed sheep, human, rabbit or rat erythrocytes after they had been incubated with a wellgrown 10-20-day-old culture of any of the six saprophytic leptospirae, showed that the lecithin and lysolecithin were largely or completely degraded. The strains Basovizza, Patoc 1, AM20 and São Paulo also partly degraded the phosphatidyl ethanolamine and phosphatidyl serine in the human, rabbit and rat erythrocytes (fig. 1), but not in sheep erythrocytes. The degradation of lecithin, phosphatidyl ethanolamine and phosphatidyl serine was activated by calcium ions. The addition of $\mathrm{CaCl}_{2}$ to the system was necessary especially for the degradation of phosphatidyl ethanolamine and phosphatidyl serine, which were not degraded to any extent in the absence of $\mathrm{CaCl}_{2}$ (fig. 1). Different cultures of the same strain of leptospira showed different activity in degrading phosphatidyl ethanolamine and phosphatidyl serine.

The activating role of calcium ions in the degradation of lecithin was clearly demonstrated in observations of the dynamics of the reaction. The degradation began earlier and proceeded more rapidly when $\mathrm{CaCl}_{2}$ was added to the system. After 72 hours' incubation, however, almost as much of the lecithin had been degraded in the system without added $\mathrm{CaCl}_{2}$ as in that with it. An activating effect of calcium ions on the degradation of lysolecithin was established only in the test with rat erythrocytes (fig. 2). In absence of $\mathrm{CaCl}_{2}$ the lysolecithin in rat erythrocytes was not degraded to any significant extent. The lysolecithin in rat erythrocytes, in contrast to the lysolecithin in the erythrocytes of the other animal species, was degraded only very slowly. No degradation of sphingomyelin was detected when the erythrocytes were incubated with saprophytic leptospirae for up to $96 \mathrm{hr}$ (figs. 1 and 2).

Under the same experimental conditions the parasitic leptospiral strains Pomona, Simon, To-Cumiana, Mezzano 1, Ndambari, Moskva V, Mallersdorf and Pavia 1 gave a partial or complete degradation of lecithin, lysolecithin and, in contrast with the saprophytic strains, sphingomyelin. Phosphatidyl ethanolamine and phosphatidyl serine were degraded completely by the strains Simon and Ndambari (fig. 3), but only partially by some cultures of the strains Pomona and Mallersdorf. The parasitic leptospirae gave the same results whether or not $\mathrm{CaCl}_{2}$ was added to the system with sheep, human and rabbit erythrocytes. Calcium ions were shown to activate the degradation of lecithin, lysolecithin, phosphatidyl ethanolamine and phosphatidyl serine only in the system with rat erythrocytes (fig. 2). The lysolecithin in rat erythrocytes was not degraded to any significant extent unless calcium ions were present.

The degradation of lysolecithin and sphingomyelin began in the first hours of incubation and proceeded rapidly; after 8-12 hr the greater part was degraded. The degradation of lecithin, phosphatidyl ethanolamine and phosphatidyl serine took a longer period; it was appreciable only after 10-12 hr, and was complete only after $24-36 \mathrm{hr}$ with strongly active strains and after 48-72 $\mathrm{hr}$ with weakly active ones. 
The parasitic strains: Monjakov DVB, Vitulina, Wjinberg, Ratto 67, Bianchi 1, RGA, Zanoni and HL26 degraded the lysolecithin (fig. 4), but not, even in $96 \mathrm{hr}$, the lecithin, sphingomyelin, phosphatidyl ethanolamine or phosphatidyl serine.

The phospholipids in osmotic haemolysis were found to be degraded by leptospiral cultures in essentially the same way as those in washed erythrocytes.

\section{Lysis of erythrocytes by leptospirae}

The saprophytic strains Basovizza, São Paulo, Patoc 1 and AM20 lysed the erythrocytes of man, rabbit and rat but not those of sheep. The strains Doberdo

TABLE I

Haemolysis of human, rabbit and rat erythrocytes by the saprophytic leptospira strain Basovizza in the absence and presence of $\mathrm{CaCl}_{2}$

\begin{tabular}{|c|c|c|c|c|c|c|c|}
\hline \multirow{2}{*}{$\begin{array}{l}\text { Species of } \\
\text { erythro- } \\
\text { cytes }\end{array}$} & \multirow{2}{*}{$\begin{array}{l}\text { Addition of } \\
\mathrm{CaCl}_{2} \text { to the } \\
\text { test mixture }\end{array}$} & \multicolumn{6}{|c|}{$\begin{array}{l}\text { Haemolysis after incubation of test } \\
\text { mixture for period (hr) }\end{array}$} \\
\hline & & 4 & 12 & 18 & 24 & 36 & 48 \\
\hline Human & $\begin{array}{l}\text { No } \\
\text { Yes }\end{array}$ & $\overline{-}$ & $\overline{-}$ & $\overline{+}$ & $\overline{+}+$ & $\overrightarrow{+}+$ & + \pm \\
\hline Rabbit & $\begin{array}{l}\text { No } \\
\text { Yes }\end{array}$ & $\overline{ \pm}$ & \pm & \pm & $\begin{array}{l}++ \\
+++\end{array}$ & $\stackrel{++}{++}$ & $\begin{array}{l}t+t \\
t+t\end{array}$ \\
\hline Rat & $\begin{array}{l}\text { No } \\
\text { Yes }\end{array}$ & $\bar{t}$ & $\stackrel{ \pm}{++}$ & ++ & $\begin{array}{l}++ \\
++\end{array}$ & $\begin{array}{l}++ \\
++\end{array}$ & $\begin{array}{l}+++ \\
++\end{array}$ \\
\hline
\end{tabular}

$-=$ No haemolysis; $t=$ trace of haemolysis; $t=$ slight haemolysis; $t+=$ strong haemolysis; $+++=$ complete or nearly complete haemolysis.

and Dindio lysed rabbit and rat erythrocytes, but not human and sheep erythrocytes. The haemolytic reaction was activated by calcium ions. In the absence of $\mathrm{CaCl}_{2}$ the saprophytic leptospirae did not lyse human red cells or lysed them only very weakly. In contrast with the parasitic leptospirae which lysed rat erythrocytes only after a prolonged incubation, the saprophytic strains lysed them very rapidly. The results obtained in tests with strain Basovizza are given in table I.

The parasitic strains Pomona, Simon, To-Cumiana, Mezzano, Ndambari, Moskva V, Mallersdorf and Pavia 1 lysed sheep, human, rabbit and rat erythrocytes. Haemolysis was not activated by addition of $\mathrm{CaCl}_{2}$. The strains Monjakov DVB, RM2, Vitulina, Wjinberg, Ratto 67, Bianchi 1, RGA, Zanoni and HL26 did not show haemolytic properties.

Lysis first became visible after different periods of incubation and then proceeded at different velocities with the red cells of the different animal species. The lysis of sheep erythrocytes occurred in the first few hours of incubation and proceeded very rapidly, but a longer period of incubation was necessary for the lysis of human, rabbit and rat erythrocytes. With strongly haemolytic 


\section{Plate I}

FIG. 1.-Thin-layer chromatography of phospholipids extracted from human erythrocytes after incubation for $72 \mathrm{hr}$ with a whole culture of the saprophytic strain Basovizza in the absence of $\mathrm{CaCl}_{2}(\mathrm{~A})$, in the presence of $\mathrm{CaCl}_{2}(\mathrm{~B})$, and with sterile Korthof's medium (C).

FIG. 2.-Thin-layer chromatography of phospholipids extracted from rat erythrocytes after incubation for $24 \mathrm{hr}$ with a whole culture of the saprophytic strain Basovizza in the absence of $\mathrm{CaCl}_{2}$ (A), in the presence of $\mathrm{CaCl}_{2}$ (B), with sterile Korthof's medium (C), and after incubation for $48 \mathrm{hr}$ with the parasitic strain Simon in the presence of $\mathrm{CaCl}_{2}$ (D) and in the absence of $\mathrm{CaCl}_{2}$ (E).

FIG. 3.- Thin-layer chromatography of phospholipids extracted from human erythrocytes after incubation for $24 \mathrm{hr}$ with sterile Korthof's medium (A), and with a whole culture of the parasitic strain Simon in the absence of $\mathrm{CaCl}_{2}$ (B).

FIG. 4.-Thin-layer chromatography of phospholipids extracted from human erythrocytes after incubation for $96 \mathrm{hr}$ with a whole culture of the parasitic strain Bianchi in the absence of $\mathrm{CaCl}_{2}$ (A), in the presence of $\mathrm{CaCl}_{2}(\mathrm{~B})$, and with sterile Korthof's medium (C).

FIGs. 1-4.-LEC = Lecithin; $\mathrm{LL}=$ lysolecithin $; \mathrm{PE}=$ phosphatidyl ethanolamine; $\mathrm{PS}=$ phosphatidyl serine; $\mathrm{SPH}=$ sphingomyelin. 
ERYTHROCYTE PHOSPHOLIPIDS AND LEPTOSPIRAE

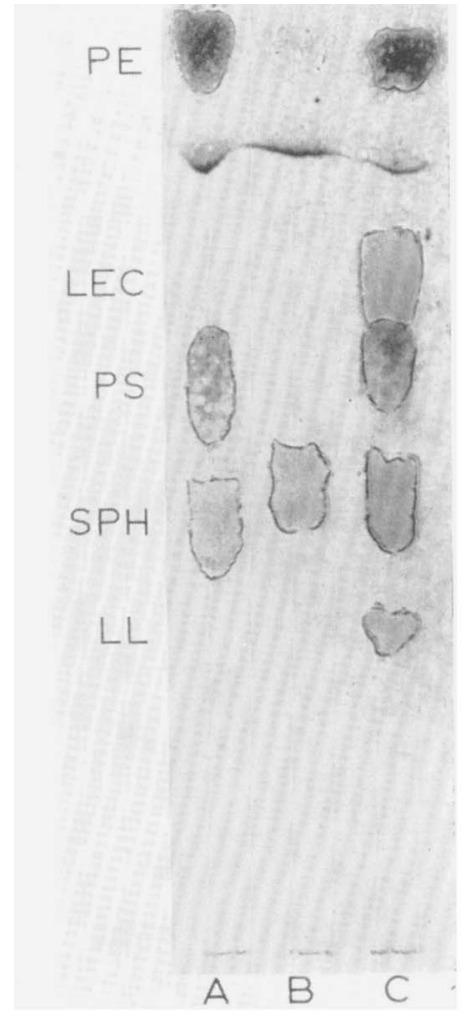

FIG. 1.

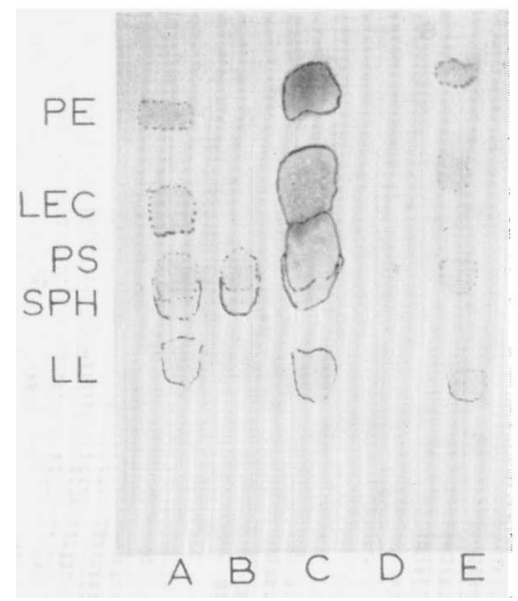

FIG. 2.

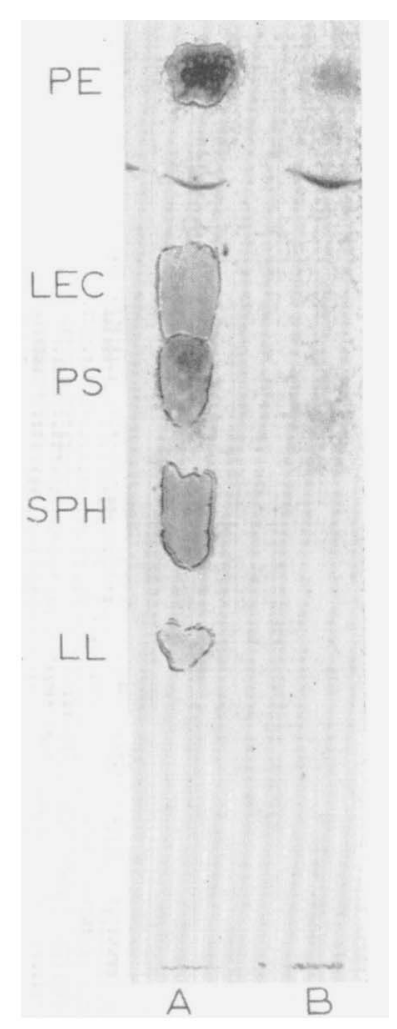

FIG. 3.

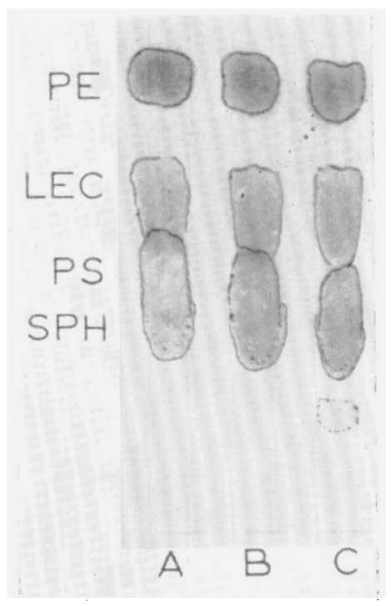

FIG. 4. 
strains, sheep erythrocytes were completely lysed in $18-24 \mathrm{hr}$, human and rabbit erythrocytes in $28-36 \mathrm{hr}$, and rat erythrocytes only after $36-48 \mathrm{hr}$. The same strains showed only very slight lysis of human, rabbit and rat erythrocytes in 10-12 hr.

In contrast with the haemolysis of sheep erythrocytes produced by the $\alpha$-toxin of Clostridium welchii (van Heyningen, 1941), that produced by leptospiral haemolysin was independent of the requirement for cooling of the haemolysin-erythrocyte mixture.

\section{Discussion}

All the main types of phospholipids in the erythrocyte membrane were found to be susceptible to the action of specific leptospiral enzymes. The phospholipids of serum lipoproteins had previously been found to be susceptible to these enzymes by Kasărov and Addamiano (1969), who classified the leptospirae into three groups according to their actions on lecithin and sphingomyelin. Group A consisted of strains degrading lecithin but not sphingomyelin, group B of strains degrading lecithin and sphingomyelin, and group C of strains degrading neither lecithin nor sphingomyelin. All the saprophytic leptospirae tested belonged to group $\mathrm{A}$ and all the parasitic leptospirae belonged either to group B or group C. The difference in the velocity of degradation of the sphingomyelin and lecithin in serum lipoproteins observed by Kasărov and Addamiano was found also for these phospholipids in erythrocyte membranes. The sphingomyelin in erythrocyte membranes was degraded much more rapidly than the lecithin, and a prolonged period of incubation was necessary for degradation of the lecithin, phosphatidyl ethanolamine and phosphatidyl serine.

The present studies established a correlation between enzymatic activity and haemolytic activity. The strains that did not degrade either lecithin or sphingomyelin (group C) showed no haemolytic activity. The strains degrading these phospholipids (group B) lysed sheep, human, rabbit and rat erythrocytes. This group includes haemolytic strains belonging to the serotypes pomona, grippotyphosa, bataviae and the serotype ndambari, which is the only known haemolysin-producing serotype in the serogroup icterohaemorrhagiae (van Riel, 1959; Kmety and Bakoss, 1961). All other strains in this serogroup that were non-haemolytic, and the non-haemolytic strains of the serotypes pomona and grippotyphosa belonged to group C (table II).

The phospholipid composition of the red cell membrane is characteristic for each animal species. There are marked differences between the species in the proportions of the main types of phospholipids, especially in those of the choline-containing phospholipids. The red cell membranes of the rat, guineapig, rabbit, man, ox and sheep reveal a progressive decrease in the content of lecithin from about 60 to 0 per cent. of the total phospholipids, and a corresponding increase in the content of sphingomyelin from 26 to 64 per cent. (de Gier and van Deenen, 1961; de Gier, Mulder and van Deenen, 1961; table III). It was found that the saprophytic leptospirae did not lyse sheep erythrocytes. Apparently their inability to degrade sphingomyelin is associated 
with their inability to attack the sphingomyelin-rich membranes of sheep erythrocytes. The erythrocytes of sheep and ox, with their large content of sphingomyelin and minimal content of lecithin are lysed by the parasitic leptospirae more rapidly than are the erythrocytes of other animal species. As has been already mentioned the parasitic strains degrade sphingomyelin much faster than the other phospholipids. The lysis of human, rabbit and rat erythrocytes, in which the amount of lecithin is greater than that of sphingomyelin, appeared only after a longer incubation than was required for lysis of sheep erythrocytes.

TABLE II

Enzymatic and haemolytic activity of parasitic leptospirae

\begin{tabular}{|c|c|c|c|c|}
\hline Group & Serotype & Strain & $\begin{array}{l}\text { Degradation of } \\
\text { choline-containing } \\
\text { phospholipids }\end{array}$ & $\begin{array}{l}\text { Production of } \\
\text { haemolysin* }\end{array}$ \\
\hline B & $\begin{array}{l}\text { pomona } \\
\text { pomona } \\
\text { pomona } \\
\text { pomona } \\
\text { ndambari } \\
\text { grippotyphosa } \\
\text { grippotyphosa } \\
\text { bataviae }\end{array}$ & $\begin{array}{l}\text { Pomona } \\
\text { Simon } \\
\text { T-Cumiana } \\
\text { Mezzano 1 } \\
\text { Ndambari } \\
\text { Moskva V } \\
\text { Mallersdorf } \\
\text { Pavia 1 }\end{array}$ & $\begin{array}{l}+ \\
+ \\
+ \\
+ \\
+ \\
+ \\
+ \\
+\end{array}$ & $\begin{array}{l}+ \\
+ \\
+ \\
+ \\
+ \\
+ \\
+\end{array}$ \\
\hline $\mathrm{C}$ & $\begin{array}{l}\text { pomona } \\
\text { grippotyphosa } \\
\text { grippotyphosa } \\
\text { copenhageni } \\
\text { copenhageni } \\
\text { icterohaemorrhagiae } \\
\text { icterohaemorrhagiae } \\
\text { zanoni } \\
\text { djatzi }\end{array}$ & $\begin{array}{l}\text { Monjakov DVB } \\
\text { RM2 } \\
\text { Vitulina } \\
\text { Wjinberg } \\
\text { Ratto } 67 \\
\text { Bianchi } 1 \\
\text { RGA } \\
\text { Zanoni } \\
\text { HL26 }\end{array}$ & $\begin{array}{l}z \\
= \\
= \\
= \\
= \\
= \\
-\end{array}$ & $\begin{array}{l}- \\
= \\
= \\
= \\
= \\
z\end{array}$ \\
\hline
\end{tabular}

* Active on sheep, human, rabbit and rat erythrocytes.

This observation agrees with Russel's (1956) finding that leptospiral haemolysin is most active on sheep erythrocytes, less active on human erythrocytes, still less active on rabbit erythrocytes, and only very slightly active on guinea-pig erythrocytes. Evidently haemolysis of the erythrocytes of animals other than ruminants cannot be demonstrated during short-term experiments of the kind generally used to demonstrate the presence of haemolysin in leptospiral cultures.

Calcium ions were found to activate both the degradation of phospholipids and the production of haemolysis by saprophytic leptospirae. This correlation supports the conclusion that the degradation of the membrane-bound phospholipids plays a primary role in the haemolysis caused by leptospirae. As has been noted, the saprophytic leptospirae did not lyse human erythrocytes in absence of $\mathrm{CaCl}_{2}$ even after incubation of $96 \mathrm{hr}$. The analysis, however, showed that during this prolonged incubation the lecithin was degraded in the absence of $\mathrm{CaCl}_{2}$. In spite of this degradation no haemolysis was observed. In the presence of $\mathrm{CaCl}_{2}$, however, phosphatidyl ethanolamine and phosphatidyl serine 
were also degraded (fig. 1) and haemolysis took place. The saprophytic strains, on the other hand, were found to lyse rabbit erythrocytes after incubation for 60-72 hr in absence of $\mathrm{CaCl}_{2}$ without degrading phosphatidyl ethanolamine and phosphatidyl serine. It seems likely that haemolysis takes place only when a certain proportion of the phospholipids of the cell membrane is degraded. Thus, lecithin constitutes 44 per cent. of the phospholipid content of the membrane of rabbit erythrocytes, but a much lower proportion of that in human erythrocytes.

TABLE III

Phospholipid content of erythrocytes of various animal species

\begin{tabular}{|c|c|c|c|}
\hline \multirow{2}{*}{$\begin{array}{l}\text { Species of } \\
\text { erythrocytes } \\
\text { (references*) }\end{array}$} & \multicolumn{3}{|c|}{$\begin{array}{l}\text { Phospholipid content of erythrocytes } \\
\text { (percentage of total phospholipid phosphorus) }\end{array}$} \\
\hline & Lecithin & $\begin{array}{l}\text { Sphingomyelin plus } \\
\text { lysophospholipids }\end{array}$ & Cephalins† \\
\hline Sheep $(4,6)$ & $0 \cdot 0 \pm 1 \cdot 0$ & $64 \cdot 0 \pm 1 \cdot 0$ & $35 \cdot 0 \pm 1 \cdot 0$ \\
\hline Ox $(2,4)$ & $7 \cdot 0$ & $59 \cdot 0$ & $34 \cdot 0$ \\
\hline $\operatorname{Man}\left\{\begin{array}{l}(4) \\
(5)\end{array}\right.$ & $\begin{array}{l}38 \cdot 5 \pm 2 \cdot 0 \\
29 \cdot 5\end{array}$ & $\begin{array}{c}36 \cdot 5 \pm 2 \cdot 0 \\
28 \cdot 7\end{array}$ & $\begin{array}{c}25 \cdot 0 \pm 3 \cdot 0 \\
38 \cdot 0\end{array}$ \\
\hline Rabbit (3) & $44 \cdot 0$ & $29 \cdot 0$ & $27 \cdot 0$ \\
\hline Guinea-pig (1) & $56 \cdot 3$ & $14 \cdot 4$ & $24 \cdot 3$ \\
\hline Rat (4) & $59 \cdot 0 \pm 3 \cdot 0$ & $26 \cdot 0 \pm 1 \cdot 5$ & $15 \cdot 0 \pm 2 \cdot 5$ \\
\hline
\end{tabular}

* (1) Condrea et al. (1964a), (2) van Deenen, de Gier and de Haas (1961), (3) de Gier, Mulder and van Deenen (1961), (4) de Gier, de Haas and van Deenen (1961), (5) Klibanksy and Osimi (1961) and (6) Turner (1957)

$\dagger$ Phosphatidyl ethanolamine and phosphatidyl serine.

The velocity of the enzymatic degradation differed not only between the different types of phospholipids, but also, in some cases, between phospholipids of the same type present in the erythrocytes of different animal species. Thus, lysolecithin in rat erythrocytes, in contrast to that in human, rabbit and sheep erythrocytes, was only very slowly degraded by the saprophytic and parasitic leptospirae. The saprophytic strains degraded the lecithin in rat erythrocytes much faster than that in the erythrocytes of other animal species. The phosphatidyl ethanolamine and phosphatidyl serine in sheep erythrocytes appeared to be resistant to degradation by saprophytic leptospirae, but, when present in rat erythrocytes, these phospholipids were degraded even in absence of $\mathrm{CaCl}_{2}$ (fig. 2). Comparable differences in the velocity of the degradation of phospholipids of the same type present in the red cells of different animal species were observed by van Deenen, de Gier and de Haas (1961) and de Gier, de Haas and van Deenen (1961) in their studies on the action of Clostridium welchii $\alpha$-toxin. These differences may depend upon structural peculiarities of the erythrocyte membranes of the different species determined by the differences in their phospholipid composition. 
Phospholipase-A fractions isolated from snake venoms have been found to differ markedly in their ability to hydrolyse the phospholipids contained in osmotic haemolysates (Condrea et al., 1964a; Condrea, de Vries and Mager, 1964b). The activity of lecithinase-C is also affected by lysed red cells. According to Macfarlane (1950) the activity of the lecithinases of $\mathrm{Cl}$. welchii and $\mathrm{Cl}$. haemolyticum was reduced by 75 per cent. in the presence of lysed sheep red cells at a final concentration of 1 per cent. Thus, in experimental mixtures the time at which the lecithinase begins to be affected may be determined by the "fragility" of the particular red cells used. The degradation of the phospholipids by leptospiral enzymes was not affected by lysed red cells.

The present results, and those of studies still in progress, indicate that the " haemolysin " of leptospirae consists of a variety of phospholipases, and that the phospholipases constituting the "haemolysin" of the saprophytic leptospirae differ from those constituting that of the parasitic leptospirae. It is evident that the haemolytic action of the leptospiral haemolysin is due to an enzymatic degradation of the phospholipids present in the membrane of the erythrocytes. The effect of the leptospiral enzymes on the erythrocytes is a very destructive one, and the enzymes of some of the strains, e.g., Simon and Ndambari, degrade all the phospholipids in the membrane.

Further investigations are required to establish to what extent these enzymes are involved in the pathogenesis of leptospirosis. The haemolytic manifestations of leptospirosis are evidently the result of the degradation of phospholipids in the membrane of the erythrocytes. It may well be that these same enzymes attack the phospholipids in the membranes of other types of cells and so are responsible for some of the other pathological changes observed in the infection.

\section{SUMMARY}

The main types of phospholipids present in erythrocytes, namely lysolecithin, lecithin, phosphatidyl ethanolamine, phosphatidyl serine and sphingomyelin, were found to be degraded by enzymes produced by parasitic and saprophytic leptospirae. No basic difference was found between the degradation of the phospholipids bound in serum lipoproteins and that of the phospholipids bound in the membranes of erythrocytes. The parasitic leptospirae were differentiated into two groups according to their ability to degrade the cholinecontaining phospholipids: (1) strains degrading lecithin and sphingomyelin, and (2) strains degrading neither lecithin nor sphingomyelin. The saprophytic leptospirae degraded lecithin but not sphingomyelin.

The activity of the enzymes of the different strains of leptospirae in degrading phospholipids was correlated with the haemolytic activity of the strains. Calcium ions were found to activate both the degradation of lecithin, phosphatidyl ethanolamine and phosphatidyl serine by saprophytic leptospirae and the haemolysis caused by these leptospirae. Calcium ions did not activate the degradation of erythrocyte phospholipids and the haemolysis caused by the parasitic leptospirae.

These findings suggest (1) that the haemolytic action of leptospiral haemolysin is due to an enzymatic degradation of phospholipids in the erythrocyte 
membrane, (2) that the " haemolysin" of leptospirae consists of more than one enzyme (phospholipase), (3) that the enzymes constituting the "haemolysin" of the parasitic leptospirae differ from those constituting that of the saprophytic leptospirae, and (4) that two main factors determine the susceptibility of erythrocytes from different animal species to the haemolytic action of leptospirae, namely, the enzyme composition of the haemolysin and the phospholipid composition of the erythrocyte membrane.

\section{REFERENCES}

AleXander, A. D., Smith, O. H., Hiatt, 1956. Proc. Soc. Exp. Biol. Med., 91, 205.

C. W., AND Gleiser, C. A.

BABUDIERI, B.

Condrea, E., Mammon, Z., Aloof, S., AND DE VRIES, A.

CONDREA, E., DE VRIES, A., AND MAger, J. 1964b. Ibid., 84, 60.

VAN DeEnen, L. L. M., DE Gier, J., AND DE HAAS, G. $\mathbf{H}$.

DE GIER, J., AND VAN DEENEN, L. L. M. .

DE GIER, J., DE HAAS, G. H., AND VAN DEENEN, L. L. M.

DE GIER, J., Mulder, I., AND VAN

DeENEN, L. L. M.

van HEYNINGEN, W. E.

JOVER, A. . . . . . .

KaSĂROV, L. B., AND AdDAMIANO, LAURA

Klibansky, C., AND OsImi, Z. .

KMETY, E., AND BAKOSS, P. . . .

Kmety, E., Plesko, I., Bakoss, P., And Chorvath, B.

Macfarlane, Marjorie G. _ . 1950. Biochem. J., 47, 270.

Marinetti, G. V. . . . . . 1962. J. Lipid Res., 3, 1.

Pentek-Juhasz, M. . . . . . 1960. Acta vet. hung., 10, 233.

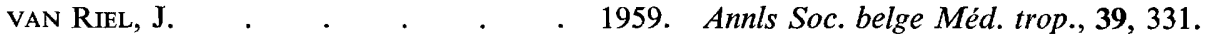

Rogols, S., Fizette, W. B., ANd Bohl, 1959. Amer.J. Vet. Res., 20, 592. E. H.

Russel, CAtherine M.

$\because \quad$ • . . . 1956. J. Immun., 77, 405.

Turner, J. C. $\quad . \quad$. $\quad . \quad \quad \cdot \quad$. 1957. J. Exp. Med., 105, 189.
1961. Bull. Wld Hlth Org., 24, 45.

1961. Proc. K. ned. Akad. Wet., Sect. B, 64, 528.

1961. Biochim. biophys. Acta, 49, 286.

Biochem. J., 81, 33.

1961. Naturwissenschaften, 48, 54.

1941. Biochem. J., 35, 1257.

1969. J. Med. Microbiol., $2,243$.

161. Bull. Res. Coun. Israel, 9E, 143. 181, 503.

1966. Annls Soc. belge Méd. trop., 46, 111.

1954. Fedn Proc., 13, 510. 